\title{
MINIIITIAN FINISHING KULIT LEMAS (SOFTY LEATHER) \\ DARI KULIT KAMBING UNTUK TAS WANITA
}

Oleh Widhiati, Emiliana K., Emy Sulistyo Astuti, Suharjono Joko Susilo, Kuwatno, Suryadi.

\section{AHAIHACI}

This tevein his is aimed at finding the competition of paint substance which optimal applied hit thily iheep leather for lady's bags manufacturing. Materials used in this study were 27 Wiein if pi. lled sheep stock and simple factorial $3 \times 3$ was use for the research plan, the Hrangang of whith is combination binder RU 3989 (150 gram, 200 gram, 250 gram) and Wiuiteni (1) grum, 100 gram, 125 gram) for 1,000 gram paint sollution. The research result

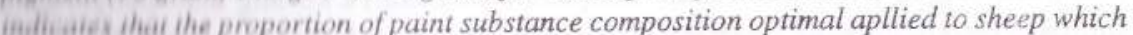
wis iugue tiu be soly leather for lady's bags manufacturing is the combination of $250 \mathrm{gram}$ Ainder 1111.1089 and 75 gram pigment in 1,000 gram paint sollution, and the test result fulfil the wiquirments of sheep garment leather quality.

\section{INIISARI}

Mnelitian ini bertujuan untuk mendapatkan perbandingan komposisi bahanbahan untuk wit iuip yang optimal bagi kulit kambing yang disamak menjadi kulit lemas untuk tas wanita. Hishen yang digunakan dalam penelitian ini adalah kulit kambing awet asam (pikel) sebanyak 1) lembir Rancangan penelitian menggunakan simple factorial $3 \times 3$ dengan perlakuan Aambinasi perekat (binder) RU 3989 (150 gram, $200 \mathrm{gram}, 250 \mathrm{gram}$ ) dan zat warna (pigmen) (1/1 gram, $100 \mathrm{gram}, 125 \mathrm{gram})$ untuk setiap 1.000 gram larutan cat tutup. Hasil penelitian meamiukkan bahwa perbandingan komposisi bahanbahan cat tutup yang optimal bagi kulit humbine vang disamak menjadi kulit lemas untuk tas wanita adalah perlakuan kombinasi ankan perekat RU 3989 sebanyak $250 \mathrm{gram}$ dan zat warna 75 gram dalam $1.000 \mathrm{gram}$ larutan cat tutup dan hasil uji memenuhi persyaratan mutu kulit jaket dari kulit domba/ Aumbing.

\section{PENDAHULUAN}

Kulit lemas (softy leather) adalah kulit yang mempunyai pegangan yang lunak, agak elastis, fleksibel $(1,3)$, tidak los, supel dan mempunyai kekuatan fisis yang tinggi (4). Agar kulit lemas tersamak dapat menarik dan awet maka perlu udinya proses penyempurnaan (finishing) dengan cat tutup. Cat tutup untuk tas harus tahan terhadap goresan, tidak luntur dan tidak mudah pecah, oleh karena itu lapisan dasar dari cat tutup harus betulbetul masuk kedalam kulit dan melekat baik pada permukaan kulit. 
Kulit kambing merupakan kulit hewan kecil (skin) yang mempunyai sifat keras, tekstur tertutup, struktur jaringan kompak, rajah bagus dan mempu-nya tegangan putus yang tinggi. Biasanya digunakan untuk pembuatan atasan sepatu, pelapis (lining), pakaian dan tas. Karena sifatsifat kulitnya yang keras dan teksturnya yang tertutup maka dalam proses peminyakannya menggunakan kombinasi berbagai tipe minyak dan jumlah minyak yang tepat, akan memberi-kan tingkat kelemasan kulit $(1,8)$. Proses pengolahan kulit merupakan suatu teknologi pengolahan dari bermacammacam proses, sedangkan proses peminyakan adalah merupakan salah satu proses yang bertujuan untuk memberi pelumas kejaringan kulit sehingga kuli menjadi lunak, lembut dan mempunyai tegangan putus yang baik serta tahan terhadap air (6). Lebih lanjut dikatakan oleh Thortensen bahwa penggunaan minyak yang tepat dapat mempengaruhi sifat fisis seperti tegangan putus, kekuatan jahit, kekuatan tarik dan pegangan kulit. Bila pemakaian minyak berlebihan maka akan menghasilkan kulit yang lemas dan kadangkadang menyebabkan warna yang kurang rata pada bagian perut dan rusuk, tetapi bila jumlahnya kurang atau penyerapan minyak (penetrasi) yang tidak tepat akan menghasilkan kulit yang keras dan dapat retak bila diterapkan pada barang jadi. kulit :

Ada 3 macam macam jenis peminyakan yang digunakan dalam penyamakan

1. Minyak "an ionik".

2. Minyak "kationik".

3. Minyak "non ionik".

Minyak "an ionik" dapat digunakan tunggal atau dicampur dengan salah satu minyak dasar dengan jumlah sedikit untuk mendapatkan hasil kulit jadi yang lembut.

Sedangkan minyak "kationik" biasanya digunakan pada akhir peminyakan dengan jumlah sedikit yang akan membantu pengurangan retaknya rajah dan memberi sifat lunak, pegangan-nya lembut dan tanpa penyerapan minyak yang berlebihan $(6,7)$. Sistim peminyakan mungkin akan baik untuk satu tipe kulit, tetapi belum tentu cocok untuk tipe kulit yang lain.

Untuk mendapatkan kulit lemas tidak hanya tergantung pada proses peminyakannya saja tetapi harus diimbangi dengan proses lainnya seperti proses pencucian (soaking), pengapuran (liming), penyamakan, penyamakan ulang serta harus ditunjang dengan ketrampilan penyamak dan sistim penyempurnaan (finishing)nya $(6,7)$.

Proses Penyempurnaan kulit adalah merupakan hal yang penting dan sangat luas artinya. Bermacammacam proses dirancang untuk menambah penampilan akhir yang menarik dan dapat dipakai sesuai dengan hasil akhir yang diinginkan.

Untuk memberikan sifat lemas pada kulit biasanya penyamak kecuali inemamiahikan bahan pelunak seperti minyak pada proses peminyakan dan lainlarn Аннина ре rekat pada proses penyempurnaan, juga menggunakan perlakuan mekanik uieiti jeregangan dengan mesin "staking" atau dengan tangan, "milling" dan mie

Proses Penyempurnaan(finishing) adalah proses akhir yang umumnya iнerapakan proses pengecatan tutup dengan menggunakan satu atau lebih bahan je mi ienuk lapisan/ perekat (binder), bahan pewarna (pigmen) dan bahan pembantu Limasik perlakuan mekanik.

Agar diperoleh hasil proses penyempurnaan yang optimal pada proses

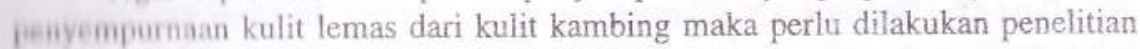
men:enai komposisi cat tutupnya.

\section{MAIICI DAN METODA}

A. MATERI.

Bahan yang digunakan pada penelitian ini adalah 27 lembar kulit kambing awet asam dengan ratarata berat perlembar adalah $0,80 \mathrm{~kg}$.

"Khemikalia" yang digunakan untuk proses dari kulit awet asam sampai iemuan kulit kras adalah : Bahan penyamak (Krom, Tannesco HN, Tanigan OS, Hetingan R7 dan mimosa ekstrak), cat dasar, minyak dan bahan-bahan pembantu. thedanykan khemikalia untuk proses penyempurnaan adalah zat warna, perekat, Lahan pengisi (filler), lak, penetrator dan larutan lak.

Peralatan yang digunakan diantaranya adalah drum penyamakan, timbangan, mangkok, pengaduk, saringan, alat semprot cat, alat pentang, drum pelemasan, mesin peregang dan mesin seterika serta alatalat untuk uji fisis dan uji kimiawi.

\section{METODA.}

Semua kulit awet asam yang telah dipersiapkan dibelah sepanjang garis punggung menjadi 2 bagian, kemudian diproses menjadi kulit lemas dengan warna coklat muda dan coklat tua.

Tahapantahapan yang dilaksanakan dalam proses adalah sebagai berikut

1. Proses pembuatan kulit lemas dari kulit kambing awet asam sampai dengan kulit kras kambing.

2. Proses pengecatan tutup (proses penyempurnaan).

1. Pengujian sifat fisis dan kimiawi.

4. Analisa data.

1. Proses pembuatan kulit lemas dari kulit kambing awet asam sampai dengan kulit kras kambing.

Vol. XII No. 24 Th. 1996/1997 
a. Penghilangan lemak (degreasing).

- $2 \%$ Iragol DA.

- $150 \%$ Air, putar 60 menit.

b. Pengasaman Ulang (repikel)

- $80 \%$ Air.

- $10 \% \mathrm{NaCl}, 10$ menit.

- $1 \%$ Asam formiat, 15 menit.

- $0,5 \%$ Asam sulfat, 45 menit, cek pH=2,5.

- $1 \%$ Tergolix AN, 60 menit.

c. Penyamakan (Tanning)

- Larutan Asam.

- $8 \%$ Chromosal B, 60 menit.

- 0,5\% Remsynol OCS, 15 menit.

- $1 \%$ Soda kue, 30 menit.

- $0,3 \%$ Anti jamur, 15 menit.

- $2 \%$ Plenasol SRB, 60 menit.

d. Proses penetralan (Netralisasi) dan Penyamakan Ulang

- $200 \%$ Air

- $3 \%$ Tanesco HN, 60 menit.

- $200 \%$ Air.

- $0,75 \%$ Asam formiat,

- $0,75 \%$ Soda kue, 60 menit.

- $2 \%$ Tanigan OS.

- $2 \%$ Retingan R7, 60 menit.

$2 \%$ Mimosa Ekstrak, 30 menit.

e. Pencucian.

$200 \%$ air, 10 menit

f. Pengecatan dasar dan peminyakan.

- $200 \%$ air.

- $1 \%$ Cat dasar, $2 \times 10$ menit.

$1 \%$ Invaderm LU, 10 menit.

- $3 \%$ Sandolix SPE $\backslash 2 \times 10$ menit, di

- $4 \%$ Sandolix AK / tambah 60 menit.

$0,5 \%$ Renmol, 30 menit.

- $0,5 \%$ Asam formiat, 15 menit, drain.
1. Top Dyeing.

$150 \%$ Air, $40^{\circ} \mathrm{C}$

$1 \%$ Cat dasar, $2 \times 15$ menit.

$0.5 \%$ Renmol, 30 menit.

$0,3 \%$ Anti jamur, 15 menit.

$0.5 \%$ Asam formiat, 15 menit, tiriskan (drain)

Kemudian kulit diperam selama 1 malam, keesokan harinya dilanjutkan dengan mekeriaan mekanik seperti : perataan permukaan (settingout), pengeringan, pelembaban, pelemasan (milling) dengan alat staking wheel, pementangan dan perapihan (triming).

Proses Pengecatan Tutup (Finishing).

Hebelum dicat tutup kulit diseterika terlebih dahulu (plate) dengan suhu $70^{\circ} \mathrm{C}$, Iekanan 50 Bar dan waktu 0 (kiss piate) untuk membatasi penyerapan larutan fat сын yang berlebihan kedalam kulit dan mempermudah pembentukan film pada permukaan.

formula dan tahapan pada proses pengecatan tutup :

A. L apisan dasar (base coat).

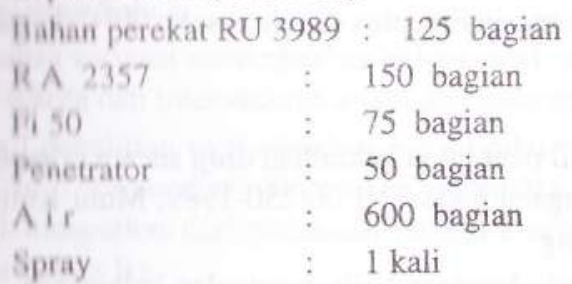

b. Lapisan tengah (pigment coat).

Dalam pemberian lapisan tengah dilakukan kombinasi perlakuan pada jumlah bahan pembentuk filem (perekat RU 3989) sebagai berikut : $\mathrm{A}=150 \mathrm{gram}$, B = 200 gram dan $C=250$ gram. Dicampur dengan bahan pewarna (pigmen) dengan ukuran sebagai berikut : $X=75$ gram, $Y=100$ gram dan $Z=125$ gram, sehingga dapat diperoleh komposisi seperti dalam tabel berikut : 
Tabel pencampuran bahan perekat RU 3989 dengan zat pewarna

\begin{tabular}{|l|l|c|c|c|c|c|c|c|c|c|}
\hline \multirow{2}{*}{ No. } & \multirow{3}{*}{ B A H A N } & \multicolumn{3}{|c|}{ A } & \multicolumn{3}{|c|}{ B } & \multicolumn{3}{c|}{ C } \\
\cline { 3 - 10 } & & X & Y & Z & X & Y & Z & X & Y & Z \\
\hline 1. & RA 2357 & 100 & 100 & 100 & 100 & 100 & 100 & 100 & 100 & \\
2. & RU 3989 & 150 & 150 & 150 & 200 & 200 & 200 & 250 & 250 & 250 \\
3. & PIGMEN & 75 & 100 & 125 & 75 & 100 & 125 & 75 & 100 & 125 \\
4. & WAXTOP B & 30 & 30 & 30 & 30 & 30 & 30 & 30 & 30 & 30 \\
5. & PENETRATOR & 25 & 25 & 25 & 25 & 25 & 25 & 25 & 25 & 25 \\
6. & Fi 50 & 50 & 50 & 50 & 50 & 50 & 50 & 50 & 50 & 50 \\
7. & AIR & 570 & 545 & 520 & 520 & 495 & 470 & 470 & 445 & 420 \\
\hline
\end{tabular}

- Lapisan atas (Top Coat)

$$
\text { LS } 859 \text { 1 bagian }
$$$$
\text { Thinner } 3 \text { bagian. }
$$

Semprot 1 kali, lemaskan (milling) selama 1 jam pentang sebentar.

LS 859 bagian.

Thinner 3 bagian.

Agensia pelicin $5 \% / 1000$ gram.

Semprot 1 kali, seterika dengan mesin Fineplex (Satilux) suhu $90^{\circ} \mathrm{C}$ dan tekanan 70 Bat.

3. Pengujian

Kulit lemas (softy leather) hasil penelitian kemudian diuji secara organoleptis, fisis dan kimiawi dengan mengacu pada SNI 06-250-1989, Mutu Kulit Jaket dari Kulit Domba atau Kambing.

Pengujian organoleptis meliputi : keadaan kulit, warna dan kelemasan.

Pengujian Fisis meliputi : tebal, penyamakan, kekuatan tarik, kemuluran, ketahanan bengkuk, ketahanan gosok cat, penyerapan air, kekuatan sobek dan kekuatan jahit.

Pengujian kimiawi meliputi : kadar air, kadar abu jumlah, kadar krom oksida, kadar minyak/lemak dan $\mathrm{pH}$.

4. Analisa Data

Kulit lemas (softy leather) dari kulit kambing untuk tas wanita hasil penelitian yang telah diuji kemudian datanya dianalisa secara statistik menggunakan faktor faktorial (simple factorial).

\section{HABII. DAN PEMBAHASAN}

Hasil penelitian yang diperoleh berupa data uji kulit lemas (softy leather), tekapuialasi hasil uji ratarata kulit lemas dari kulit kambing (softy leather) untuk tan wasica ierdapat pada lampiran 1.

Demikian pula tabel analisa varians uji kekuatan tarik, kemuluran, kekuatan lahii dan penyerapan air. Sedangkan hasil analisa varians dengan metode simple fai linial diperoleh hasil sebagai berikut :

1. Kekuatan Tarik.

Analisa variansi menunjukkan bahwa tidak ada beda. nyata baik pada variasi 1mekai, zat warna maupun interaksinya terhadap kekuatan tariknya. Hasil fenelitian menunjukkan bahwa nilai ratarata kekuatan tarik $=2.469,14 \mathrm{~N} / \mathrm{cm}^{2}$. Негані semua perlakuan kombinasi permakaian perekat dan zat warna dapat dimanakan yaitu: AX, AY, AZ, BX, BY, BZ, CX, CY dan CZ.

Kemoluran

Amalina variansi menunjukkan bahwa tidak ada beda nyata pada variasi perekat dain fat warna, tetapi ada beda nyata pada interaksi antara perekat dengan zat warna. Ilasil penelitian menunjukkan bahwa nilai rata-rata kemulurannya = $30,17 \%$. Ditinjau dari nilai rata-rata kemulurannya maka nilai yang paling baik didapakkan pada perlakuan CX yaitu $=57,5 \%$.

1. Kekiaian Sobek

Anatian variansi menunjukkan bahwa tidak ada beda nyata pada variasi jumlah fai warna dan interaksinya tetapi ada beda nyata pada variasi perekat.

Ifail penelitian menunjukkan bahwa nilai rata-rata kekuatan sobek $=237,27$ $\mathrm{N} / \mathrm{C}$ im. Ditinjau dari nilai rata-rata kekuatan sobeknya maka nilai yang paling haik didapatkan dari perlakuan dengan kombinasi perekat RU 3989200 bagian (jerlakuan B)

4. Kekuatan Jahit.

Amalisa variansi menunjukkan bahwa tidak ada beda nyata pada variasi perekat tan zat warna serta interaksi antara perekat dan zat warna.

Hissil penelitian menunjukkan bahwa nilai ratarata kekuatan jahit $=1.286,36 \mathrm{~N} /$ fii. Herarti semua perlakuan kombinasi pemakaian perekat dan zat warna dapat dimunakan yaitu : AX, AY, AZ, BX, BY, BZ, CX, CY dan CZ.

1. Penyerapan Air, 2 jam dan 24 jam.

Amalisa variansi menunjukkan bahwa tidak ada beda-nyata pada variasi perekat dan zat warna $(P, 0,05)$ tetapi ada beda nyata pada interaksi antara perekat dan fai warna ( $\mathrm{P} \mu 0,05)$. Hasil penelitian ini menunjukkan bahwa nilai uji ratarata ןенуегараn air selama 2 jam $=180,34 \%$. Nilai yang paling baik didapat dari Hila ratarata penyerapan air air 2424 jam $=185,17 \%$ didapat dari perlakuan kumhinasi RU 3989 zat warna 250 bagian, zat warnat 75 bagian.

Kil Xil No. 24 Th. 1996/1997 


\section{KESIMPULAN}

Dari hasil penelitian dapat disimpulkan bahwa ternyata perbandingan komposisi cat tutup/proses penyempurnaan kulit lemas dari kulit kambing yang optimal adalah perlakuan kombinasi pemakaian zat warna 75 bagian dan perekat RU 3989250 bagian dengan formulasi sebagai berikut :

- Zat pewarna (pigmen) 75 bagian

- RA $2357 \quad 100$ bagian

- RU $3989 \quad 250$ bagian

- Relcasyn Wax Top B 30 bagian

- Penetrator 25 bagian

- Fi $50 \quad 50$ bagian

- Air 470 bagian

Sebagai cat tutup teratas (top coat), komposisi bahan adalah sebagai berikut :

- L S 859

- Super Thinner Gloss 3 bagian

- Agensia pelicin KS $132 \quad 5 \% / 1.000$ gram.

Hasil uji kulit lemas dari kulit kambing ini telah memenuhi persyaratan mutu kulit jaket dari kulit domba/kambing.

\section{DAFTAR PUSTAKA}

1. Briggs P S, 1981, Glocing, Clothing and Special Leathers, Tropical Products Institute, England.

2. Daftar Istilah-istilah mengenai Kulit Jadi (Leather), British Standard, 2780, 1972.

3. Departemen Perindustrian, SNI. 062501989, Mutu Kulit Sarung Tangan dan Jaket dari Kulit Domba dan atau Kambing.

4. Finishing Supple Chrome Leather, International Journal of The Industry, Vol 179 No. 4420, February 1977, Halaman 37 dan 39.

5. Moslem Ali, Fat Liquor Phenomena, Pakistan Leather Trade Journal, Paris Leather Fair 1988, Reg. No. 158, Vol. 15 No. 3.

6. Nowak R, New Tendencies Fat Liquoring of Leather, Pakistan Leather Trade Journal, Paris Leather Fair, September 1987.

7. Thorstensen T, 1985, Practical Leather Technology, Robert E. Krieger, Publishing Company, Malabar, Flotida.

8. Tuck D.H, 1981, The Manufacture of Upper Leather, Tropical Product Institute, England. 